\title{
Ambiente virtual de ensino-aprendizagem em dispositivos móveis para o curso de comércio exterior
}

\author{
Hamlet Xavier Simon ${ }^{1}$
}

\begin{abstract}
Resumo: As tecnologias digitais de informação e comunicação revolucionam, a cada instante, as relações e interações entre os docentes, discentes e, especialmente, os recursos utilizados para os processos educativos. Isto não ocorre somente nos ambientes tradicionais de ensino, mas também na forma mais ubíqua de se trabalhar com o ensino-aprendizagem em rede. Destaca-se o desenvolvimento e a operacionalização de módulos educacionais em rede através da plataforma Moodle - software livre e mediador-chave de instituições de ensino superior, os quais permitem potencializar o conhecimento discente a partir da prática, da interação e da produção colaborativa. Utilizamos a pesquisa-ação educacional em cinco ciclos espiralados, acoplada à customização de tecnologias, como a inclusão de recursos educacionais específicos acessados através de dispositivos móveis. Os resultados configuram-se com o aprimoramento da prática docente e inovando-se no planejamento de disciplinas com conteúdo prático para o curso de comércio exterior. A evolução passa pela mudança na prática pedagógica, evoluindo-se do conteúdo transmitido de forma bancária, para a lógica da resolução de problemas.
\end{abstract}

Palavras-chave: Tecnologias digitais de informação e comunicação. Recursos educacionais. Dispositivos móveis. Comércio Exterior.

\section{Virtual environment of teaching-learning in mobile devices for the foreign trade course}

Abstract: Every moment, the digital information and communication technologies revolutionize the relations and interactions between the teachers, students and, especially, the used resources for the educational processes. This occurs not only in traditional teaching environments, but also in the ubiquitous way of working with teaching-learning network. We highlight the development and operationalization of educational modules through the Moodle platform - free software and mediator key of higher education institutions, which allows enhancing students' knowledge based on practice, interaction and collaborative production. We used educational action research in five spiral cycles, coupled with the technologies customization, such as the inclusion of specific educational resources accessed through the mobile devices. The results configure with the improvement of teaching practice and disciplines planning innovation with practical content for the course of foreign trade. The evolution goes through the change of pedagogical practice, evolving from the content transmitted in a banking way, to the logic of solving problems.

Key-Words: Digital information and communication technologies. Educational resources. Mobile devices. Foreign trade.

\section{Ambiente virtual de enseñanza-aprendizaje en dispositivos móviles para el curso de comercio exterior}

Resumen: A cada instante, las tecnologías digitales de información y comunicación revolucionan las relaciones e interacciones entre los docentes, los discentes y, especialmente, los recursos utilizados para los procesos educativos. Esto no ocurre solamente en los ambientes tradicionales de enseñanza, sino también en la forma más ubicua de trabajar con la enseñanza-aprendizaje en red. Se destaca el desarrollo y la

\footnotetext{
${ }^{1}$ Graduado em Adninistração de Empresas - Comércio Internacional - Unisinos. Mestrado em Tecnologias Educacionais em Rede. Docente no Curso de Administração da Faculdade Antonio Meneghetti, AMF.
} 
operación de módulos educativos en red a través de la plataforma Moodle - software libre y mediador clave de instituciones de enseñanza superior, los cuales permiten potenciar el conocimiento discente a partir de la práctica, de la interacción y de la producción colaborativa. Utilizamos la investigación-acción educativa en cinco ciclos, acoplados a la personalización de tecnologías, como la inclusión de recursos educativos específicos accedidos a través de dispositivos móviles. Los resultados se configuran con el perfeccionamiento de la práctica docente e innovándose en la planificación de disciplinas con contenido práctico para el curso de comercio exterior. La evolución pasa por el cambio en la práctica pedagógica, evolucionando del contenido transmitido de forma bancaria, a la lógica de la resolución de problemas.

Palabras clave: Tecnologías digitales de información y comunicación. Recursos educativos. Dispositivos móviles. Comercio Exterior.

\section{Introdução}

O modelo de escola proposto no século XIX, com uma lousa, um docente ensinando e uma turma, aparentemente, homogênea de discentes, está sofrendo mudanças nestes últimos anos. A escola atual necessita estar mais próxima da descoberta, da ciência, da pesquisa, da curiosidade e da construção do conhecimento. O docente é, na maioria das vezes, decisivo para a construção do conhecimento, pois inegavelmente é um mediador para o efetivo aprendizado. O seu papel atual está muito distante daquele de 150 anos atrás, visto que, hoje, o conhecimento está disponível em todo o lugar, principalmente nos meios digitais, mas de forma desorganizada. Cabendo ao docente filtrar, trabalhar, dar ordem e sentido aos saberes, oportunizando ao discente novas possibilidades de ações.

Entretanto, a presente tecnologia necessita ser vista como uma ferramenta para uma evolução educacional e não o seu objetivo principal, pois ela não é o conteúdo. A gestão e o desenvolvimento de tecnologias educacionais em rede fazem parte deste desafio evolutivo para a inovação e a democratização escolar, sendo inegável que a cada dia novas tecnologias e recursos educacionais são desenvolvidos para a estruturação de cursos através de Ambientes Virtuais de Ensino-Aprendizagem (AVEA). Não menos importante é oferecer ao docente que atua na modalidade presencial Recursos Educacionais Abertos (OECD, 2008) através de ferramentas digitais e virtuais, os quais devem permitir potencializar a sua tarefa de problematizador e mediador, auxiliando na construção do conhecimento discente.

Neste contexto, os cursos de comércio exterior atualmente existentes são jovens e essencialmente teóricos, com poucas atividades práticas e dialógicas, buscando formar e qualificar profissionais dotados de discernimento político, social e econômico que lhes permita analisar as questões internacionais em vários seguimentos. Este trabalho visa, portanto, oferecer contribuições embasadas nos resultados de Pesquisa-Ação Educacional (PAE) no escopo do curso, trazendo propostas pedagógicas em busca de melhorias no 
processo de ensino-aprendizagem através da promoção da prática dialógica-problematizadora (FREIRE, 1967) e a colaboração discente.

Na prática, o objetivo deste trabalho foi o desenvolvimento e a operacionalização de módulos didático-metodológicos no ambiente virtual de ensino-aprendizagem em dispositivos móveis no curso, trabalhando com recursos educacionais em rede no conjunto ambientedispositivo móvel-curso. Dentro destes módulos foram realizados experimentos práticos de investigação, tornando a proposta didática, virtual e funcional para dispositivos móveis.

A relevância deste trabalho está na inserção de tecnologias educacionais no curso, as quais permitem avanços e trazem contribuições a todos os agentes envolvidos e atuantes no processo de ensino-aprendizagem. Desta forma, problematizou-se o aprendizado com práticas colaborativas através de ambiente virtual de ensino-aprendizagem acessados através de dispositivos móveis, ampliando-se o alcance e a equidade da educação, através de comunidades de aprendizado, otimizando-se o tempo de aula e propiciando o acesso ao conhecimento a qualquer hora, em qualquer lugar e para todos os discentes do curso.

\section{Referencial Teórico}

\subsection{Metodologia de pesquisa e a implementação de ações}

Os cinco ciclos espiralados da pesquisa-ação educacional (CARR e KEMMIS, 1986), acoplada à customização de tecnologias, foram utilizados como metodologia para este trabalho, com a inclusão de recursos educacionais específicos acessados através de dispositivos móveis e estruturados no Moodle (DOUGIAMAS, 2003). Buscou-se a inovação através da contextualização de módulos educacionais em rede no tripé “ambiente virtual dispositivos móveis - para cursos de graduação e especialização em comércio exterior. No planejamento de cada módulo procurou-se promover o entendimento e o domínio das regras internacionais para o comércio entre país e blocos econômicos, gerando procedimentos documentais e operacionais de forma crescente e sequencial, onde o módulo anterior tornavase a base para o módulo seguinte.

Os módulos constituem-se de 5 aulas para uma disciplina de Logística Internacional, as quais totalizaram 20 horas de pesquisa com ações especificamente programadas. A estruturação de cada aula representa um módulo e cada módulo representa um ciclo de nossa pesquisa. 
Tabela 1 - Cronograma de operacionalização dos módulos didático-metodológicos

\begin{tabular}{ccc}
\hline Módulos/Aulas & Ciclos & Data de operacionalização \\
\hline \hline 6 & $1^{\circ}$ & $08 / 05 / 2017$ \\
7 & $2^{\circ}$ & $15 / 05 / 2017$ \\
8 & $3^{\circ}$ & $22 / 05 / 2017$ \\
9.1 & $4^{\circ}$ & $29 / 05 / 2017$ \\
9.2 & $5^{\circ}$ & $05 / 06 / 2017$ \\
\hline
\end{tabular}

Fonte: Elaborado pelo autor.

Para que pudéssemos situar aos discentes os módulos didáticos dentro de uma disciplina de Logística Internacional no Moodle acessada através de dispositivos móveis, foi necessário descrevermos o plano de ensino da disciplina. Totalizamos 16 (dezesseis) encontros presenciais durante todo o semestre, sendo os primeiros 6 (seis) encontros com conteúdos fundamentados em conceitos básicos e descritivos dos elementos atuantes na estrutura produtiva empresarial e nacional. Estes conceitos e descrições são dos processos administrativos e procedimentos operacionais, usualmente adotados no comércio exterior.

Os módulos desenvolvidos foram trabalhados com os discentes semanalmente, considerando-se o movimento dialógico-problematizador com suas etapas: (I) Recurso Educacional: acessado pelo discente, foi produzido a partir de uma situação real ou circunstancial da prática e concreta; (II) Desafio Inicial: é composto pelo envolvimento discente na resolução de um problema ou desafio proposto pelo docente, referente ao conteúdo proposto e apresentado na aula presencial; (III) Diálogo-Problematizador: é a problematização com os discentes, analisando e dialogando sobre as resoluções produzidas por eles; (IV) Desafio Mais Amplo: é a construção ou a formulação colaborativa de questões e situações-limite frente à situação-problema ou desafio proposto inicialmente; (V) Atividades extraclasse: são tarefas para casa (homeworks), em pares ou individuais, para a apropriação do conhecimento apresentado em sala de aula - no contexto seguinte e recursos prévios da próxima aula.

O quadro a seguir (1) objetiva apresentar a estruturação e a organização de cada módulo da pesquisa, cada qual representado por uma aula. $\mathrm{O}$ quadro constitui-se de colunas que reúnem as respectivas informações sobre o planejamento proposto para o módulo, o recurso educacional utilizado, as atividades ou suas resoluções postadas pelo discente no Moodle (DOUGIAMAS, 2003), e, por fim, o resultado de aprendizado esperado para o módulo. 
Quadro 1 - Planejamento, Recursos, Atividades e Resultado de Aprendizagem Esperado de cada ciclo ou módulo educacional.

\begin{tabular}{|c|c|c|c|}
\hline $\begin{array}{c}\text { Planejamento } \\
\text { disponível no Moodle }\end{array}$ & Recurso no Moodle & $\begin{array}{l}\text { Atividades } \\
\text { no Moodle }\end{array}$ & $\begin{array}{l}\text { Resultado de } \\
\text { Aprendizagem } \\
\text { Esperado }\end{array}$ \\
\hline I) Recurso educacional. & $\begin{array}{l}\text { REA. } \\
\text { (Textos e vídeos) }\end{array}$ & $\begin{array}{l}\text { Apresentação de recurso } \\
\text { educacional aos discentes. } \\
\text { (Reunidos em pares) }\end{array}$ & Conhecimento teórico. \\
\hline II) Desafio Inicial. & & $\begin{array}{l}\text { Tarefa - resolução em pares } \\
\text { discentes do desafio inicial } \\
\text { (online). }\end{array}$ & $\begin{array}{l}\text { Resolução de um } \\
\text { problema - prática. }\end{array}$ \\
\hline $\begin{array}{l}\text { Diálogo sobre a resolução discente } \\
+ \text { apresentação de conteúdo } \\
\text { docente. }\end{array}$ & $\begin{array}{l}\text { Arquivo - Power Point do } \\
\text { docente incluindo REA. } \\
\text { Aula - recorte temático. }\end{array}$ & & $\begin{array}{l}\text { Reflexão discente sobre o } \\
\text { conteúdo. }\end{array}$ \\
\hline III) Desafio mais amplo. & & $\begin{array}{l}\text { Tarefa - resolução em pares } \\
\text { discentes do desafio mais } \\
\text { amplo (online). }\end{array}$ & $\begin{array}{l}\text { Retrospecção e avaliação } \\
\text { conscientizadora do } \\
\text { realizado. }\end{array}$ \\
\hline $\begin{array}{l}\text { IV) Atividades extraclasse } \\
\text { (homeworks). }\end{array}$ & $\longrightarrow$ & $\begin{array}{l}\text { Tarefa - resolução em pares } \\
\text { discentes da tarefa } \\
\text { extraclasse (online). }\end{array}$ & Conteúdo complementar. \\
\hline
\end{tabular}

Fonte: Elaborado pelo autor.

Em cada módulo procurou-se promover:

- O diálogo-problematizador com os discentes, com a análise e o diálogo sobre as resoluções produzidas por eles;

- A inserção de Recursos Educacionais Abertos (REA), os quais devem seguir os elementos básicos necessários e definidos pela OECD (2008);

- A reflexão crítica discente sobre o seu aprendizado e a sua interação com os demais discentes do grupo.

Como Ambiente Virtual de Ensino Aprendizagem (AVEA) utiliza-se o Moodle, por ser o ambiente virtual mais utilizado no ensino superior brasileiro, seja na modalidade presencial, semipresencial ou a distância. Trata-se de um software livre de código aberto, cujas atualizações colaborativas e constantes proporcionam o acesso a um conjunto significativo de ferramentas e aplicações contemporâneas, de forma online e com destacada interatividade e interação hipermidiática (DOUGIAMAS, 2003). 
Através da Figura 1 a seguir, mostra-se a tela inicial da disciplina acessada através de um dispositivo móvel (smartphone), cujo objetivo é ressaltar as caraterísticas do Moodle e a funcionalidade móvel buscada ao incorporarmos tais dispositivos na educação superior.

Figura 1 - Área de trabalho do Moodle com a página inicial da disciplina no curso de comércio exterior em smartphone 5,5"

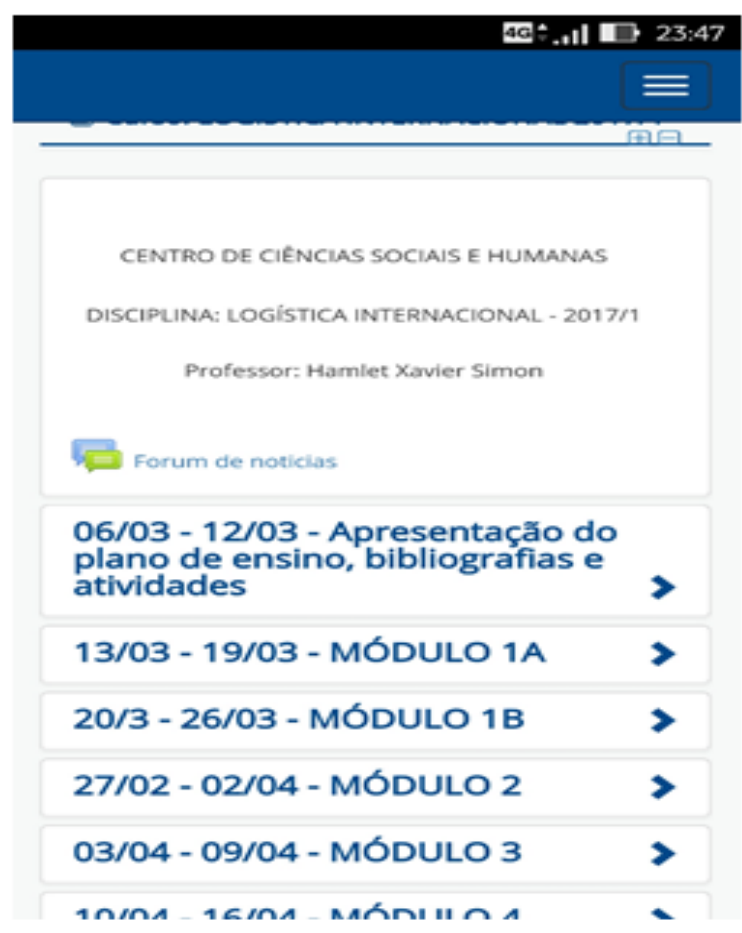

Fonte: Moodle ead06, my (2017).

Dentro de cada módulo desenvolvido e operacionalizado foram realizados experimentos práticos de investigação tornando a proposta didática, virtual e funcional para dispositivos móveis. Com o desenvolvimento e a gestão destes módulos educacionais em rede operando em dispositivos móveis, cria-se e otimiza-se conteúdos educacionais abertos, problematizando-se o aprendizado através de práticas colaborativas, visto que os smartphones são mediadores exemplares de comunicação cotidiana.

Inicia-se cada módulo com a apresentação aos discentes do planejamento do encontro e de um recurso educacional aberto com o recorte temático proposto. Na sequência imediata, e como desafio inicial aos discentes, propõe-se a resolução de um problema sobre o recurso educacional disponibilizado. Nesta problematização inicial, prioritariamente em pares, os discentes devem escolher a melhor solução para o pontuado problema, justificando a resposta apresentada. Em um segundo momento, o docente inicia a apresentação do conteúdo da aula, 
abrindo-se em seguida o diálogo-problematizador entre os discentes. Este diálogo tem como objetivo promover a análise sobre o recorte temático e a solução escolhida pelos pares na resolução do problema apresentado como desafio inicial, bem como analisar as justificativas para as escolhas realizadas. No final deste encontro presencial, como desafio mais amplo propõe-se aos discentes a realização de um trabalho em pares, constituindo-se da formulação pelos discentes de um novo problema a ser resolvido, devendo ser considerado um processo diferente do anterior, aplicando-se a solução encontrada e analisada no desafio inicial, com a respectiva justificativa para a proposta apresentada pelos pares.

Através da Figura 2 a seguir, apresenta-se a tela com parte dos módulos do curso e a estrutura de um deles, acessados através de um dispositivo móvel (smartphone), cujo objetivo é ressaltar a estrutura desenvolvida e operacionalizada, bem como a funcionalidade móvel desejada ao incorporarmos tais recursos através dos dispositivos na educação superior.

Figura 2 - Área de trabalho no Moodle em smartphone 5,5" exemplificando um módulo educacional - um ciclo de pesquisa-ação.

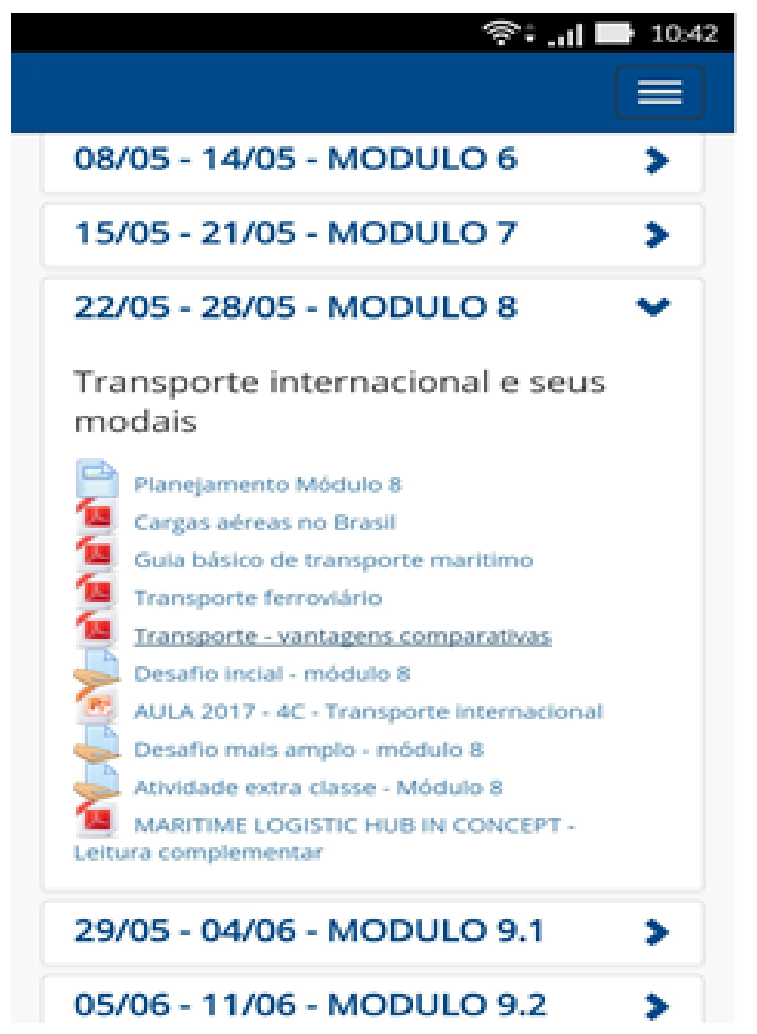

Fonte: Moodle ead06, my (2017). 
Ao estruturar-se o conjunto de módulos educacionais procurou-se construir, através de conteúdos correlatos e sequencialmente interdependentes, objetivos a serem alcançados a partir de níveis de criticidade analítica e, a partir destes, elaborar novos conhecimentos discentes. A construção dos saberes discentes, nos 5 ciclos ou conjunto de módulos de pesquisa-ação, está alicerçada na prática e no diálogo-problematizador.

\section{Resultados e discussão}

Os movimentos de retrospecção e prospecção em cada módulo trabalhado permitiram, através desta Pesquisa-Ação Educacional, identificar algumas respostas para a melhoria da disciplina. Da mesma forma, permitiram analisar os recursos e atividades utilizadas através do processo de desenvolvimento colaborativo.

Os resultados obtidos apontam, conclusivamente, que este trabalho foi impactado pela dificuldade de acesso efetivo e constante a uma internet de qualidade e pelas dificuldades observadas na utilização dos smartphones de forma online. Por consequência, foi limitada a possibilidade de disponibilizar aos discentes um maior número de diversificados recursos educacionais, bem como acessarmos sistemas online de emissão de documentos. Ao analisarmos estas limitações a partir do ponto de vista do Movimento do Software Livre (STALLMAN, 2010), as restrições observadas e anotadas, mesmo que relativas, comprometeram o cumprimento do papel docente de disseminar o conhecimento para os discentes e torná-los, desta forma, membros plenamente capacitados e atuantes em suas comunidades.

Apesar destas limitações terem sido observadas desde o início do curso e da pesquisa, no planejamento, o trabalho colaborativo discente é um dos fundamentos básicos a ser buscado. Para isto, partiu-se com a formação de pares discentes desde os primeiros encontros presenciais, com o objetivo de executar atividades escolares, mantendo-os em pares até o término dos encontros. Esta iniciativa teve como intuito a construção da consciência colaborativa e que, pelo menos em sala de aula, deveria promover a colaboração em contraponto à formação individualista e competitiva recebida pelos discentes até então.

Ao planejar os módulos educacionais, preocupou-se em promover a prática e a experimentação com a produção discente conforme o projeto em pares. Esta produção baseouse em situações desafiadoras mediadas pelo docente, contextualizados através de "casos práticos" ou "exemplos relacionados", os quais foram apresentados pelo docente durante o diálogo-problematizador, validação crítica discente. Com isto, concluiu-se que esta 
contextualização foi fundamental em nosso contexto de pesquisa-ação educacional (PAE), em especial, no escopo da investigação-ação.

Por fim, na etapa da reflexão coube ao docente refletir sobre os fatos e situações que ocorreram, provenientes da ação e observações realizadas, com o intuito de reestruturar ou reconstruir a fase ou ação para o ciclo seguinte. Foram nestes momentos de reflexão, em seu respectivo ciclo, que decidiu-se pela: (I) inserção de recursos educacionais abertos, produzidos pelo docente, a partir de sua prática e conhecimento sobre o estudo proposto; (II) iniciativa docente de verificar, durante o intervalo do encontro, as resoluções do Desafio Inicial (DI) postadas pelos discentes no Moodle em sala de aula, possibilitando, assim, uma melhor avaliação dos pontos essenciais a serem utilizados no diálogo-problematizador e no Desafio mais Amplo (D+A); e, (III) a inserção pelo docente de "casos práticos" ou "exemplos relacionados" aos diálogos, contextualizando e melhorando a compreensão e a apreensão discente sobre o estudo proposto.

$\mathrm{Na}$ prática docente, procurou-se estruturar a conduta em sala de aula (docência) em concomitância à conduta em relação à pauta dialógica (investigação) e, desta forma, obter-se respostas mais consistentes em relação aos objetivos e os ciclos espiralados de nossa pesquisa-ação. Estes ciclos, embasados nos trabalhos dos autores Carr e Kemmins (1986), constituíram-se das etapas de planejamento, ação, observação e reflexão, onde o movimento de retrospecção, acoplado à prospecção, procurou viabilizar a transformação da prática educacional e o processo emancipatório discente.

\section{Conclusão}

Ao desenvolvermos este trabalho procurou-se referenciá-lo a partir de um importante campo de estudo, teorias, ideias e pensadores, os quais são utilizados como base para inúmeras e diversificadas pesquisas no âmbito educacional. Estas referências teóricas nos permitiram compreender os principais conceitos ligados à liberdade, à colaboração, ao compartilhamento e à conscientização crítica, delineando este trabalho e as respectivas ações necessárias para que alcançássemos os nossos objetivos.

Ao buscarmos saber quais as potencialidades teóricas, práticas, de inovação e democratização, relacionadas à gestão das tecnologias educacionais em redes virtuais, através de dispositivos móveis no curso, concluímos que a utilização destes equipamentos por meio de uma plataforma de gestão de ensino não é o fator determinante para a melhoria no 
aprendizado discente. Estes são apenas tecnologias complementares, que visam auxiliar na promoção de uma educação de qualidade.

Por mais que vivenciemos uma revolução tecnológica, a evolução terá que ser pedagógica, mesmo que esta seja suportada pelos meios digitais. A evolução passa pela mudança na prática pedagógica, evoluindo do conteúdo transmitido de forma bancária, para a lógica da resolução de problemas. Não basta utilizarmos em sala de aula a mais moderna plataforma de gestão educacional e conteúdos atualizados para que possamos afirmar que estamos proporcionando uma educação de qualidade e emancipatória. Com a conduta docente, de somente disponibilizar os recursos educacionais, as atividades a serem executadas ou para mera comunicação com os discentes, manter-se-á intocável à forma bancária de transmissão de informações.

Ressaltadas as observações e as limitações apresentadas neste trabalho, concluímos que há um expressivo potencial teórico e principalmente prático na gestão de tecnologias educacionais em rede virtual - Moodle, (DOUGIAMAS, 2003) através de dispositivos móveis. O conjunto de módulos didático-metodológicos, desenvolvidos e operacionalizados, podem ser utilizados como base para a formatação de outros cursos, sejam eles teóricos ou com possibilidades práticas.

Resolvidas ou mesmo minimizadas as observações e as limitações observadas durante a pesquisa, já considerando a mudança na postura docente, pode-se obter um salto qualitativo ainda maior no ensino e na aprendizagem do curso. O diálogo e a participação discente promoveriam o trabalho colaborativo, a apreensão do conhecimento e sua conscientização crítica. Para o docente, permitiria a análise e a reflexão sobre a sua prática pedagógica, possibilitando uma constante atualização dos recursos utilizados, da sua conduta em sala de aula e, consequentemente, um acréscimo na qualidade do ensino em sua disciplina e no curso.

\section{Referências}

CARR, W.; KEMMIS, S. Becoming Critical: education, knowledge and action research. London, Brighton: Falmer Press, 1986. 246 p.

DOUGIAMAS, M.; TAYLOR, P. C. Moodle: Using Learning Communities to Create an Open Source Course Management System. Proceedings of the EDMEDIA, Conference, Honolulu, Hawaii. 2003. Disponível em: $<$ https://dougiamas. com/archives/edmedia2003/>. Acesso em: 11 abr. 2016. 
FREIRE, P. Educação como Prática da Liberdade. Rio de Janeiro, RJ: Editora Paz e Terra, 1967. Disponível em: http://www.dhnet.org.br/direitos/militantes/paulofreire/ livro freire educacao pratica liberdade.pdf. Acesso em: 16 mar. 2016.

OECD. EI conocimiento libre y los recursos educativos abiertos, Centro de Nuevas Inicitivas, Espanha. 2008. Disponível em: <https://www.oecd.org/spain/_42281358.pdf>. Acesso em: 24 maio 2016.

STALLMAN, R. M. Free Software, Free Society: Selected Essays. Free Software Foundation, Inc. Boston, USA, 2010. Disponível em: $<$ https://www.gnu.org/doc/fsfs- ii2.pdf>. Acesso em: 29 maio 2016. 